\title{
RACE, RHEUMATISM AND GROWING PAINS
}

\author{
BY \\ J. C. HAWKSLEY, M.D., M.R.C.P., \\ Resident Medical Officer, Children's Hospital, Birmingham.
}

A survey of the literature on diseases of children reveals the fact that there is a widely-held opinion that children of one type are more prone than those of other types to rheumatism in its various forms. The description of the incriminated type, however, varies so much with different writers as to make correlation difficult. Further, but few writers quote positive evidence in support of their opinions.

Three different types are described and may be thus summarized :-

(1) The blond and blue-eyed child, with delicate skin and pink cheeks.

(2) The brunette, with dark hair and eyes, long lashes, white skin and good complexion. The sclerotics are often bluish and the upper central incisor teeth massive. They are usually well developed.

(3) The red-haired and freckled child.

To accept all three types as predisposed to rheumatism would be to accept the larger part of the child population, and would thus defeat any object that the recognition of such a diathesis might have.

Consideration of the traits mentioned reveals that the first is descriptive of the Nordic child, the second of the Iberian or Mediterranean child, and the third of a type that may be found associated with more than one race, but is common in certain localities of Great Britain, such as parts of Wales.

In making any attempt to assess the value of these descriptions, it must be remembered that a child showing the traits of one race may none the less have an anthropological ancestry by no means pure. Further, the social and geographical factors at work make comparisons of children in different centres an unsatisfactory proceeding.

Investigations. - In an attempt to obtain data for a preliminary survey of this problem 891 children have been seen in attendance at two hospitals; 505 in London and 386 in Birmingham. An attempt has been made to divide them into broad anthropological types by means of their colouring. Such an attempt is open to two inaccuracies : first, the personal factor of the observer, 
and secondly the classification of cases with traits on the borderline of two types; but in the absence of more accurate methods this cannot be avoided, and any conclusions arrived at must be recognized as reached by a scientifically imperfect method.

The red-haired type could not be classified by hair colour into a separate group racially. The majority, whose hair shaded imperceptibly into light brown or other directions, were grouped by their other traits and a very small number with bright red hair and eyes of green, mixed or indeterminate hue have been omitted.

The children seen tended to fall into three distinct categories.

(1) Blue eyes, and flaxen or light brown hair. These have been taken as representing the Nordic type.

(2) Brown eyes and dark brown or black hair. These have been taken as representing the Iberian type.

(3) Brown eyes and light brown hair. These may be regarded as either mixtures of the other two, or, in casas where brachycephaly is marked, as having an Alpine element.*

In the first group of 505 cases in London ${ }^{1}$ the history of growing pains was inquired into as an indication (we now think wrongly) of a rheumatic tendency. The results were :-

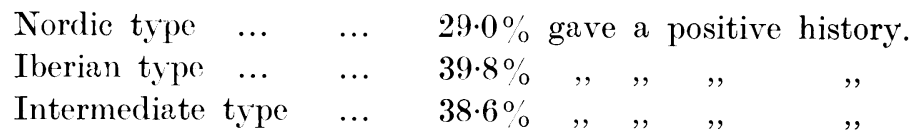

In a second saries of 206 cases in Birmingham a similar inquiry yielded :-

Nordic type $\quad \ldots \quad 33.0 \%$ gave a history of growing pains.

Medit?rranean type $57.7 \%,,,,,, \quad, \quad$,

Intermediate type $48 \cdot 8 \%,,,,,, \quad,, \quad,$,

In a third saries of 180 cases səen in the wards of the Birmingham Cinildren's Hospital over a period of six months the percentage of Nordics was :-

$\begin{array}{lcccc}\text { Acute rhcumatism and chorea }(52 \text { cases }) & \ldots & 65 \cdot 4 \% \\ \text { Other ailments (138 cases) } & \ldots & \ldots & \ldots & 63 \cdot 0 \%\end{array}$

In the first 505 children the ages ranged from 4 to 14 , in the rest 4 to 12 years inclusive.

Discussion.-From this saries it would appear that there is no increased tendency of the Nordic child to acute rheumatism or chorea, but that in the case of what is called growing pains (in this case pains in the limbs which could not be explained on any other ground) there is a tendency for the other types to be more often affected.

\footnotetext{
*Blue eyes and dark brown or black hair were rarely seen, only 6 cases in 505. These have not been classified.
} 
Shrubsall ${ }^{2}$ analysed 133 cases of rheumatism, and comparing his findings with Beddoes' analysis of 6,000 Londoners, drew the conclusion that 'the blonde traits are associated with acute rheumatism, heart disease, and tonsillitis.' Mackintosh ${ }^{3}$ has justified these conclusions by a survey of the history of the Nordic race and has pointed out that they are not physically suited to the geographical and climatic conditions associated with rheumatism.

Gray Hill ${ }^{4}$, and Gray Hill and Mary Allan ${ }^{5}$ in an examination of a large series of cases at Queen Mary's Hospital, Carshalton, and the Downs Hospital, Epsom, were unable to find any evidence to indicate the existence of a rheumatic type.

In the case of acute rheumatism and chorea our small series agrees with the much fuller findings of Gray Hill and Mary Allan, whose observations cover some 950 or more rheumatic children, and a series of controls. When, however, growing pains are investigated, we find in two səries in different cities that the Nordic is not so prone to them as the Intermediate or Mediterranean types.

If growing pains are ætiologically related to rheumatism, then it would appear that darkness of colour is related to incidence, but if there is no such relation some other explanation must be found.

Cameron and others have expressed the view that 'growing pains' are often caused by acidosis or ketosis in children of a lively type, who rapidly deplete their body glycogen when called upon to be energetic.

Pearson and $\mathrm{Wyllie}^{6}$ in discussing aspects of child-type, describe on one side of the normal, the 'acid or hypercalcic' child, and express the view that this type is more prone to rheumatism. Their hypercalcic type fits the brunette type of the rheumatic diathesis (already described) more nearly than the other types. It thus seems coriceivable that the preponderance of growing pains in darker children may be related to metabolic, and not rheumatic, causes.

Another aspect of interest is the amount of pain required to impinge upon the consciousness of the child. In an unpublished series of cases of female children we endeavoured to ascertain the solf-control of different types when pain was inflicted. The result showed the Nordic child to have an average self-control very much greater than that of darker types. It is possible that another factor in the explanation of our figures is the greater apparent sensitivity to pain of the more pigmented child.

\section{Summary.}

1. We are unable to confirm the view that the Nordic child is predisposad to rheumatism.

2. Evidence is produced to the effect that 'growing pains' are commoner in Mediterranean and Intermediate types of children than in Nordics.

3. It is suggested that the greater frequency of 'growing pains' in the more pigmented types of child is due to metabolic or constitutional factors rather than an increased susceptibility of rheumatism. 


\section{REFERENCES.}

1. Hawksley, J. C., Brit. Med. J., London, 1929, ii, 558.

2. Shrubsall, F. C., St. Barth. Hosp. Rep., Lond., 1904, XXXIV, 63.

3. Mackintosh, J. S., Clin. J., Lond., 1911, XXXVIII, 280.

4. Hill, N., Brit. J. Child. Dis., Lond., 1928, XXV, 270.

5. Hill, N. G., \& Allan, M., Brit. Med. J., London, 1929, ii, 449.

6. Pearson, W. J., \& Wyllie, W. G., Recent. Adv. in Child. Dis., Lond., 1928. 